\title{
The Causes of Malaysian and Indonesian Pilgrims' Hospitalization during the Hajj Season 1440 (2019) in Mena and Arafat Hospitals
}

\author{
Prof. Dr. Sharifah Ezat Wan Puteh ${ }^{1 *}$, Abdulaziz Abdullah Al Salem², Najibah Ali Radwan ${ }^{3}$, Siti Dahliah Ahmad Zannah ${ }^{4}$
}

${ }^{1}$ Department of Community Health, the Medical center PPUKM Faculty of Medicine, The National University of Malaysia

${ }^{2}$ Department of Community Health, the Medical center PPUKM Faculty of Medicine, The National University of Malaysia

${ }^{3}$ Ministry of Health, Saudi Arabia

${ }^{4}$ International Open University England

DOI: $10.36348 /$ sjbr.2020.v05i06.003

| Received: 30.05 .2020 | Accepted: 08.06.2020 | Published: 12.06 .2020

*Corresponding author: Prof. Dr. Sharifah Ezat Wan Puteh

\section{Abstract}

2 Malaysian and 31 Indonesian pilgrims, most of them were older than 50 years hospitalized to the seasonal hospitals in Hajj season 1440-2019. The total number of hospitalization in the targeted hospitals are 1398 Pilgrims according to M.O.H census. 1398 out of total number of pilgrims 2,489,406 (0.05\%). The common causes of Malaysian and Indonesian pilgrims' admission in Mena and Arafat hospitals with referral are Cardiac diseases; 4 cases (0.28\%), Indonesian patients; 4 cases, Nephrological disorders included Dialysis; 1 case $(0.07 \%)$, Indonesian patients; 01, and pulmonary diseases; 9 cases $(0.64 \%)$, Malaysian patient; 1 case, and for Indonesian patients; 8 . As well gastrointestinal diseases; 15 cases (1.07\%), for Malaysian patient; 1, and Indonesian patients is 14 cases. The highest and the Most common causes are pulmonary and gastrointestinal diseases. The collected data and diagnosis data were collected from admission registry, discharge summary, and report of Saudi health minister's Closing Press Release on 1440H.-Hajj Season, 2019. 13 August, 2019.

Keywords: Common; Cause; Hospitalization; Pilgrims; Malaysia; Indonesia Hajj season2019.

Copyright @ 2020: This is an open-access article distributed under the terms of the Creative Commons Attribution license which permits unrestricted use, distribution, and reproduction in any medium for non-commercial use (NonCommercial, or CC-BY-NC) provided the original author and source are credited.

\section{CHAPTER I \\ INTRODUCTION \\ BACKGROUND}

Hajj is the largest annual gatherings in the Islamic world. Hajj is the fifth pillar of Islam and is performed by all Muslim adults at least once in their lifetime provided they have the means and are physically fit to travel to Mecca. Hajj takes place on a fixed date of five to six days between the 8th and the 13th days in the month of Dhu al-Hijjah, the twelfth month in Muslim calendar. Muslims depend on the Islamic lunar calendar or known as the Hijri calendar to perform Hajj, in which the Hijri calendar is shorter than the Gregorian calendar by 10 or 11 days. Therefore, the period to perform Hajj falls 10 or 11 days earlier each year. This inconsistency caused climatic difference occurred from one hajj season to another, and thus affects the types of diseases in different climatic season. During hot weather, heat-related diseases become a common health problem during Hajj. Approximately 3 million pilgrims perform Hajj every year. Planning for health care requires knowledge of the pattern of diseases, complications, and outcome of pilgrims who require hospitalization during the Hajj period. Hajj has to be performed in three main locations in Makkah: the sacred Kaaba (in the holy city of Makkah), and Mena and Arafat, which are approximately 5 and 18 kilometers from Makkah.

The World Health Organization (WHO) would like to congratulate the Government of Saudi Arabia and the Ministry of Health for successfully hosting the hajj season 1440/2019 without a single public health event or disease outbreak being reported among pilgrims performing the hajj [1].

There are four hospitals in Mena-Mena General hospital, Mena Aljisr, Mena Alwadi, and Mena Almahbat, and four hospitals in Arafat, Arafat General hospital, Jabal Alrahmah hospital, and Namera Hospital. The hospitals in Mena and Arafat are temporary health care facilities that provide essential medical services to pilgrims during the Hajj season only. The hospitals in Mena begin operation on the seventh of Dhul-Hijjah month and close on the evening of the thirteenth, whereas Arafat hospitals operate for one day only, the ninth day of Dhul-Hijjah, as pilgrims stay in Arafat only from sunrise to sunset of that day. 
Upon closure of these hospitals, patients who cannot be discharged are transferred to permanent tertiary health care facilities in Makkah for further management,7045 Pilgrims are seen by Al Madinah hospitals physicians, 175 of them were admitted to the hospitals, and 157
Pilgrims were transferred from Al Mdinah to Makkah By ambulances [2]. As shown in figure: 1.1. This study will identify the most common causes of hospitalization ofMalaysian and Indonesian pilgrims during the Hajj season 1440 [2].

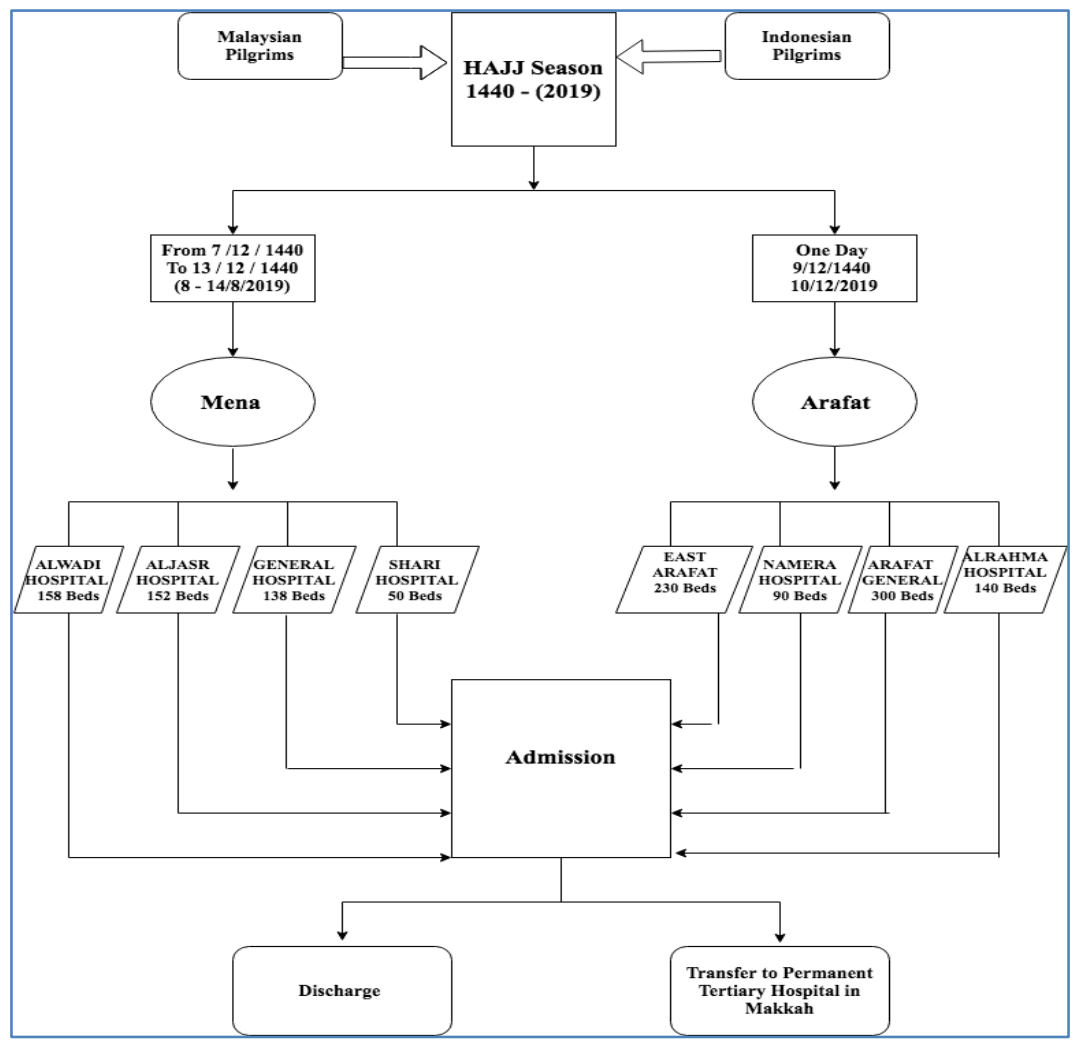

Fig-1.1: Malaysian and Indonesian pilgrims' hospitalization journey

\section{RESEARCH JUSTIFICATION}

Annually, millions of Muslims embark on a religious pilgrimage called the "Hajj" to Mecca in Saudi Arabia. The mass migration during the Hajj is unparalleled in scale, and pilgrims face numerous health hazards. The extreme congestion of people and vehicles during this time amplifies health risks, such as those from infectious diseases that vary each year. To review the most common types of hospitalization and the communicable and non-communicable hazards that pilgrims face. With the rise in global travel, preventing disease transmission has become paramount to avoid the spread of infectious diseases, including SARS (severe acute respiratory syndrome), avian influenza, and haemorrhagic fever. The study was identified the most common causes of hospitalization of pilgrims during the Hajj season 1440 [2].

The outcomes of this research are expected to help decision makers of healthcare system, and healthcare system legislators and supervisory agencies to focus on the findings of this study that will help in Mass Gathering Medicine. Hence, results of this research can be utilized for planning the public healthcare system in the next Hajj seasons.
The Malaysian mission for pilgrimage was awarded the title of "Best pilgrimage Mission" by many official institutions and religious scholars through the years as their organization and discipline catch the eyes of all Muslims from all over the world and the credit for their organization goes to Tabung Haji (TH). And Indonesia is the world's most populous Muslim nation, and it also provides the largest number of pilgrims for the hajj.

\section{Research Question}

What are the most common causes of hospitalization of Malaysian and Indonesian pilgrims during the Hajj season?

\section{Research Objective}

To identify the most common causes of hospitalization of Malaysian and Indonesian pilgrims during the Hajj season 1440 [2]

\section{CHAPTER II}

\section{LITERATURE REVIEW} INTRODUCTION

According to study was conducted in 2013 to determine the type of health-related problems among Malaysian pilgrims and to identify the health care 
services required by them during Hajj in Makkah. The large population of human congestion in Makkah during Hajj would promote contagious diseases. Thus, the pilgrims require health care services that are efficient, effective, and high quality. A cross-sectional study was conducted in which involved 379 Malaysian pilgrims in 2013/14234H. The survey was conducted after the pilgrims completed their Hajj ritual. A total of 400 sets of questionnaires were distributed at Abraj Janadriyah Hotel, which was occupied by more than 3000 Malaysian pilgrims. The response rate for this survey was $93 \%$. Male respondents were constituted of $49.6 \%$ and female respondents were $50.4 \%$ with the mean age 52 years old. The underlying disease among Malaysian pilgrims during Hajj was respiratory disease (77.5\%). The demands for health personnel $(36.1 \%)$ and quality medication $(34.7 \%)$ are among the important healthcare services required by the Malaysian pilgrims in Makkah. Respiratory disease is a common disease experienced by Malaysian pilgrims in Makkah. A certain types of services such as health personnel and quality medicine are strongly demanded by the Malaysian pilgrims to overcome their health problem during Hajj. This research provides a fundamental input to the health care providers, and also benefited the Hajj management authority to improve the quality of hajj management in future [3].

Acute respiratory symptoms are among of the most common problems faced by Hajj pilgrims who frequently need medical attention. Respiratory diseases were the most common cause of admission to hospital, with pneumonia being the leading reason for admission in $39 \%$ of all patients. 1 Over the years, approximately 25,000 Malaysian Hajj pilgrims travel to Makkah, Kingdom of Saudi Arabia. They are managed by the Malaysian Hajj Fund (Tabung Haji), a government linked company to take care of Malaysian Hajj pilgrims. A cross-sectional study was conducted among 2,000 Malaysian Hajj pilgrims from 23rd December 2007 to 23rd January 2008. Ethical approval was obtained from the UniversitiSains Malaysia Research and Ethics Committee. Informed consents were obtained from the participants. Survey forms were distributed at Madinatul-Hujjaj, Jeddah, and Tabung Haji Clinic, Madinah, Saudi Arabia where pilgrims stayed on transit before returning to Malaysia. The response to the survey was on voluntary basis. The inclusion criteria were Malaysian citizens that performed Hajj in the 2007M/1428H Hajj season, coming back via Madinatul-Hujjaj, Jeddah, or Madinah, Saudi Arabia, and with at least one respiratory symptom. The exclusion criteria were Hajj pilgrims who could not read or write in the Malay language. Data were entered and analyzed using the SPSS software (SPSS, Chicago, USA) version 12.0. Results were expressed in terms of the number and percentage. For continuous variable, they were categorized in groups and analyzed similar to categorical variables. A p-value of $<0.05$ was considered to be statistically significant. Out of 394 pilgrims that returned the completed questionnaires, $375(95.2 \%)$ had one or more respiratory symptoms, and were included in the study. These were: 355 cough, 308 runny noses, 230 fevers, and 222 sore throat. Sixty-one $(16.3 \%)$ were taking self-medication, $278(74.1 \%)$ sought treatment from a Tabung Haji clinic; $11(2.9 \%)$ were admitted to hospital, and $62(16.5 \%)$ did not take any treatment for acute respiratory symptoms. Some of them sought more than one type of treatment. There were significantly more Hajj pilgrims with cough $(\mathrm{p}=0.011)$, runny nose $(\mathrm{p}=0.040)$, sore throat $(\mathrm{p}=0.012)$, and fever $(\mathrm{p}=0.001)$ attending the Tabung Haji clinic. There were also significantly more patients with cough for more than 2 weeks $(\mathrm{p}=0.037)$, and runny nose more than 2 weeks $(\mathrm{p}=0.002)$ attending the Tabung Haji clinic. There was no significant association between any respiratory symptoms with self-treatment and hospital admission (Table 1). As a field clinic, the Tabung Haji clinic could cater to respiratory symptoms among Malaysian Hajj pilgrims. The Hajj pilgrims with respiratory symptoms were significantly seeking treatment at the Tabung Haji clinic [4].

Table-2.1: Total number of pilgrims in Ten years $1430-1439(2009-2018)$

\begin{tabular}{|c|c|}
\hline Number of pilgrims & Years \\
\hline $2,313,278$ & $1430(2009)$ \\
\hline $2,789,399$ & $1431(2010)$ \\
\hline $2,927,717$ & $1432(2011)$ \\
\hline $3,161,573$ & $1433(2012)$ \\
\hline $1,980,249$ & $1434(2013)$ \\
\hline $2,085,238$ & $1435(2014)$ \\
\hline $1,952,817$ & $1436(2015)$ \\
\hline $1,862,909$ & $1437(2016)$ \\
\hline $2,352,122$ & $1438(2017)$ \\
\hline $1,371,675$ & $1439(2018)$ \\
\hline
\end{tabular}

Source: www.stats.gov.sa/en/page/206 
Table-2.2: Total hospitalized cases in Hajj season 1439- 2018.

\begin{tabular}{|c|c|}
\hline \multicolumn{2}{|c|}{ Total admitted cases in Hajj season 1439- 2018. } \\
\hline Total cases of admission & 2142 \\
\hline Total delivery cases & 11 \\
\hline
\end{tabular}

Source: www.moh.gov.sa

Table-2.3: Total pilgrims of the year 1439 (2018)

\begin{tabular}{|c|c|c|c|c|}
\hline \multirow{2}{*}{$\begin{array}{c}\text { Total pilgrims of the } \\
\text { year } 1439(2018)\end{array}$} & \multirow{2}{*}{$\begin{array}{l}\text { Total External } \\
\text { pilgrims }\end{array}$} & \multirow[t]{2}{*}{ Asian Countries } & \multicolumn{2}{|c|}{ Non Saudis domestic pilgrims in 1439 - (2018) } \\
\hline & & & Malaysian & Indonesian \\
\hline \multirow{2}{*}{$\begin{array}{c}2,371,675 \\
(163 \text { Countries })\end{array}$} & \multirow{2}{*}{$\begin{array}{l}1,758,722 \\
(74.15 \%)\end{array}$} & \multirow{2}{*}{$\begin{array}{l}1,049,496 \\
(59.7 \% .)\end{array}$} & 464 & 1,945 \\
\hline & & & $\begin{array}{c}\text { Male: } 246 \\
\text { Female: } 218\end{array}$ & $\begin{array}{c}\text { Male: } 947 \\
\text { Female: } 998\end{array}$ \\
\hline \multicolumn{3}{|c|}{$\begin{array}{l}\text { Total Malaysian and Indonesian pilgrims of the year } 1439 \\
\text { (2018) }\end{array}$} & 23,789 & 173,293 \\
\hline
\end{tabular}

Source: www.stats.gov.sa/en/page/206

As shown in table 2.2. The percentage of total Asian pilgrims of the year 1439 (2018) is $59.7 \%$ to the total external pilgrims. And $74.15 \%$ is percentage of total external pilgrims to the total pilgrims of the year 1439 (2018).

More than two million Muslims visit Makkah, Saudi Arabia, annually to perform the religious rituals of Hajj where the risk of spreading respiratory infections is very common. The aim here was to screen symptomatic pilgrims for Middle East respiratory syndrome coronavirus (MERS-CoV) and other viral etiologies. Thus, 132 nasopharyngeal samples were collected from pilgrims presenting with acute respiratory symptoms at the healthcare facilities in the holy sites during the 5 days of the 2014 Hajj season. Samples were tested using real-time reverse transcription polymerase chain reactions and microarray. Demographic data including age, sex, and country of origin were obtained for all participants. While we did not detect MERS-CoV in any of the samples, several other viruses were detected in $50.8 \%$ of the cases. Among the detected viruses, $64.2 \%$ of the cases were due to a single-virus infection and $35.8 \%$ were due to the coinfections with up to four viruses. The most common respiratory virus was influenza A, followed by non-MERS human coronaviruses, rhinoviruses, and influenza $\mathrm{B}$. Together, we found that it was not MERS-CoV but other respiratory viruses that caused acute respiratory symptoms among pilgrims. The observed high prevalence of influenza viruses underscores the need for more effective surveillance during the Hajj and adoption of stringent vaccination requirements from all pilgrims [5].

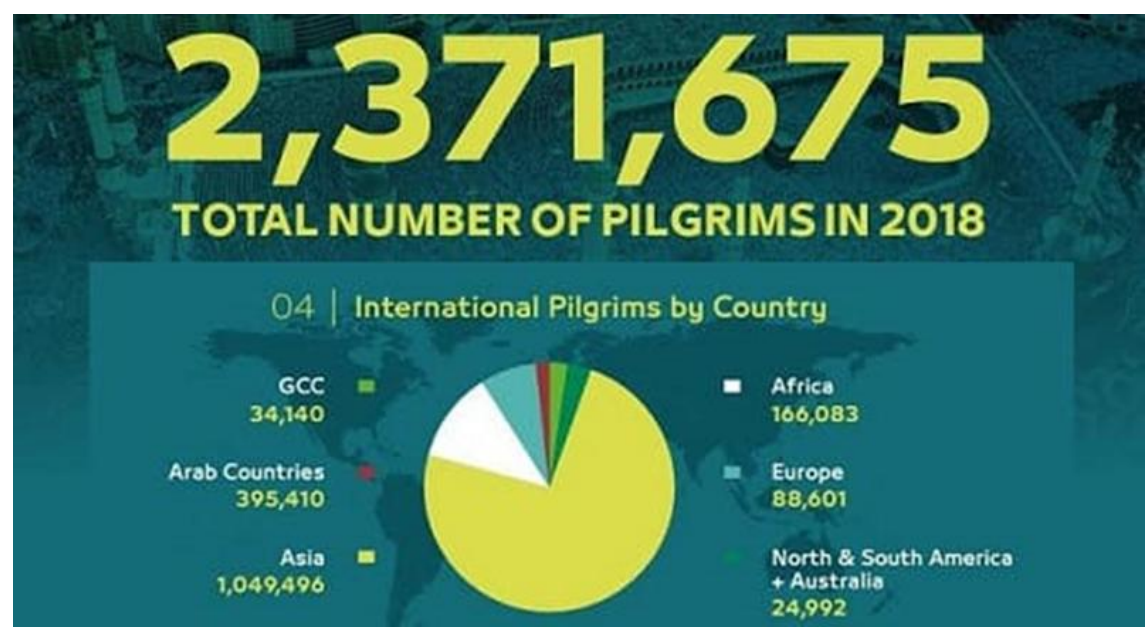

Source: $\underline{w w w . s t a t s . g o v . s a / e n}$

To determine the common health problems e.g. diseases and emergency incidents encountered by pilgrims during Hajj was the main objective of this study. An extensive literature review to determine the common health problems and emergency incidents during Hajj was conducted through a systematic literature review. Every year 2-3 million pilgrims with different background and most of them are elderly from
184 countries in the world congregate in the holy place 'Haram' at Makkah in Saudi Arabia to perform Hajj. During the pilgrimage, they come across a great deal of rough and tough environment, physical hassle and mental stress. Due to the hardship of travel, fluctuation of weather, continuous walking during religious rites at specific time and sites, many pilgrims injury, feel tired, sick, and exhausted. These may also create 
complications and overburden the physiological functions including heart, chest, abdominal, and kidney of those who suffer from chronic diseases. Besides the problem of diseases, crowds could cause some other significant problems including missing and lost pilgrims, injuries, and even death. Numerous scholarly databases were used to search for articles published related to health problems and emergency incidents during Hajj from 2008 to 2016. Eligible articles included case reports, experimental and no experimental studies. Only thirty articles out of two hundred and sixty articles had met the specific inclusion criteria. The analysis revealed that respiratory diseases include pneumonia, influenza, and asthma (73.33\%) were the main health problems encountered by the pilgrims during Hajj followed by heat stroke or heart attack, sunlight effects (16.67\%), cardiovascular disease, heart disease (10\%). The analysis also revealed that emergency incidents include traffic accidents, and trauma was $3.33 \%$. Notwithstanding the information given above, according to the analysis, the common health problems during Hajj are mainly divided into two categories: non-communicable diseases (62.5\%) and communicable diseases (37.5\%). IBM's statistical package for the social sciences (SPSS) version 22 was used to analysis the result [6].

A cross-sectional study conducted on all patients admitted to 1487 beds in four hospitals in Mena (793 beds) and three hospitals in Arafat (694 beds) from the seventh to the thirteenth day of the Hajj season of the Islamic year 1423 , corresponding to 8 to 14 February 2003. Of 808 patients hospitalized, most (79\%) were older than 40 years. There was no sex preponderance. A total of $575(71.2 \%)$ patients were admitted to medical wards, $105(13.0 \%)$ to surgical wards, and $76(9.4 \%)$ to intensive care units. Most patients $(84.8 \%)$ had one acute medical problem. Pneumonia (19.7\%), ischemic heart disease $(12.3 \%)$, and trauma $(9.4 \%)$ were the most common admitting diagnoses. More than one third (39\%) had co-morbid conditions. A total of $644(79.7 \%)$ patients were discharged from the hospital in stable condition to continue therapy in their residential camps, 140 (17.3\%) were transferred to other hospitals in Makkah for specialized services or further care, 19 (2.3\%) were discharged against medical advice, and 5 (0.7\%) patients died.This study provided information on the most common causes of hospitalization, pattern of diseases, and required medical services for pilgrims in Hajj. It is hoped that this data will be of help to health sector planners and officials to provide optimal and cost-effective health care services to pilgrims in Hajj. A total of 808 patients were admitted to the study hospitals. Four hundred and twenty-two (52.2\%) patients were from Arabic countries, 206 (25.5\%) patients were from the Indian subcontinent, 68 (8.4\%) patients were from Africa, 55 (6.8\%) patients were from east Asia, 30 (3.7\%) patients were from north Asia, 23 (2.8\%) patients were from Europe, and 4
$(0.5 \%)$ patients were from North America and Australia [7].

According to study conducted between August and October 2015, to describe inpatient clinical conditions at an advanced care facility in Saudi Arabia during the annual Hajj pilgrimage and to determine factors correlating with length of stay (LOS).With retrospective cross-sectional study, demographic, administrative and clinical data were collected from patient charts and analyzed.A total of 296 inpatients were included in the study, of which the majority were male $(73.6 \%)$ and $\geq 55$ years old $(77 \%)$. Walk-in admissions occurred less frequently than referrals (38.9\% versus $61.1 \%$ ). Most patients (41.6\%) were admitted during the peak Hajj period (the $8-13^{\text {th }}$ days of Dhu al-Hijjah). Acute coronary syndrome was the most prevalent provisional diagnosis $(65.2 \%)$. In terms of outcomes, $89.2 \%$ of the inpatients were discharged in a stable condition, with $37.5 \%$ discharged within $\leq 24$ hours of admission. However, $39.9 \%$ required admission to the Intensive Care Unit (ICU). Overall, LOS was significantly associated with various factors, including the mode of admission, admission period, admitting department, number of comorbidities and ICU admission $(P<0.050$ each).Most of admissions were referrals, and the main Hajj period witnessed the majority of admissions. The vast majority of inpatients eventually discharged in a stable condition. Determinants of the length of hospital stay were the mode of admission, admission period, admitting department, number of comorbidities and ICU admission [8].

The diagnosis and treatment of pneumonia in mass gathering situations is a medical challenge, requiring prompt decision making and knowledge of the aetiology. We studied cases of pneumonia admitted to two hospitals during the 1994 pilgrimage (Hajj) season to Makkah. Sixty-four patients were enrolled in the study, of which $47(75 \%)$ were men with a mean age of 63 years (range 21-91). Nearly all were from developing countries. Diagnosis was established in 46 patients $(72 \%)$ with Mycobacterium tuberculosis being the commonest causative organism $(20 \%)$, followed by gram-negative bacilli (18.8\%). Streptococcus pneumoniae accounted for only $10 \%$, with Legionella pneumophilia, Mycoplasma pneumoniae, and viruses accounting each for $6 \%$. The main finding of this study is that M. tuberculosis is a common cause of pneumonia under these unusual "extreme circumstances". Its presentation was acute and indistinguishable from pyogenic pneumonia. Thirty-one per cent of tuberculous cases had upper lobe involvement, 54\% lower lobe, and $15 \%$ multi-lobar. This was similar to the radiographic features in non-tuberculous pneumonia cases. All but one patient with tuberculosis recovered following the administration of first-line antituberculous drugs. The total mortality was $17 \%$. The preponderance of $\mathrm{M}$. tuberculosis and Gram-negative 
bacteria over S. pneumoniae may reflect the prior use of amoxycillin and the effect of exhaustion, malnutrition, and old age [9].

To establish the pattern of admission during this mild weather and to elucidate the possible risk factors. Study was conducted to establish the pattern of medical conditions necessitating admission differs according to the weather condition in that particular year. Previous studies had been conducted during the hot weather, none over the last 10 years, were carried out during, the milder weather we are experiencing. A prospective study was performed in 4 hospitals in 2 different locations in Al-Mashaer, Kingdom of Saudi Arabia. Data were collected during one working shift in 2 hospitals in Arafat on the 9th of DhulHijjah 1422, corresponding to 21 st of February 2002, and another working shift in 2 hospitals in Mina on the 10th of DhulHijjah 1422, corresponding to 22nd of February 2002.A cohort of 76 patients from Arafat hospitals and 84 patients from Mina hospitals were included (total 160 patients). Males constituted $62 \%$ and females $38 \%$ with the median age of $60+/-15$ years. The respiratory system was the most commonly affected (57\%), followed by cardiovascular system (19.4\%), and gastrointestinal tract (GIT) in $6.3 \%$ of cases. There were only 3 cases of heat-related admissions with only one confirmed case of heat stroke. Similarly, only one case of meningitis was confirmed in this cohort. Pneumonia was encountered in 63 cases $(39.4 \%)$ and exacerbation of asthma and chronic obstructive pulmonary diseases (COPD) in 23 cases (14.4\%). Preexisting co-morbid medical conditions had included bronchial asthma and COPD (22.5\%), hypertension $(17.5 \%)$, and Diabetes mellitus (15\%). Short-term follow up (24-48 hours) identified 2 deaths (1.3\%), 94 patients $(59 \%)$ were transferred to other secondary or tertiary care facilities and $64(40 \%)$ were discharged home. Hospital admission during Hajj is related to old age and occurs in patients with associated co-morbid conditions. During this mild weather lower respiratory tract infections and exacerbation of bronchial asthma and COPD are the most commonly encountered diseases during Hajj [10].

A review of the literature shows that our knowledge of the epidemiology of heat illnesses on a global and regional level is still lacking. Until now most of the information has come from the experience of European armies in hot environments. Recently increased interest has been shown following the epidemics of heat illnesses affecting civil communities in the United States. Of great importance and unique for the study of heat illness is the start of the hot cycle of the Makkah Pilgrimage which will continue for the next 15-16 years. Approximately two million people, the majority of whom are at great risk, will be exposed to the extremes of hot weather in May-September. Thousands of heat stroke cases are expected to occur. In this paper the conditions prevailing during the annual
Makkah Pilgrimage are described as well as a review of the epidemiological and clinical findings observed by the author during the pilgrimages of 1980/81 when 176 cases and 467 cases of Heat Stroke were seen and treated respectively and a new physiological method of treatment of heat stroke which proved very successful in clinical field trials was introduced [11].

Meningococcal meningitis epidemics, which occurred in the Kingdom of Saudi Arabia (KSA) coincided with Hajj and Umra seasons; the 2 major pilgrims to Muslims. In many countries, the disease showed major changes of its epidemiological determinants, in particular to age and prevailing serogroup. This study was conducted to determine the epidemiological trend of meningococcal meningitis disease in KSA. All confirmed meningococcal meningitis cases reported in KSA during the period from January 1999 to December 2002 were studied retrospectively. Confirmation of cases was based on isolation of the causative organism from cerebrospinal fluid (CSF) or blood culture or detection of antigen in the CSF. Personal, clinical and laboratory results were analyzed using Epi info version 6 software. Categorical data were tested using chi2 test.A total of 729 cases were reported, 304 cases (42\%) were among people coming from abroad for Hajj or Umra and 425 (58\%) were among local population. Nearly half of the later $(48 \%)$ were reported at the 2 holy areas of Makkah and Madinah, KSA. Thirty-nine percent of cases were children aged $<2$ years and $58 \%$ were $<5$ years of age. Proportion of cases affected with serogroup W135 increased over time (up to $95 \%$ ) and significantly affected children aged $<5$ years $(\mathrm{p}<0.001)$ [12].

\section{"Statistics": More Than 32,500 Employees Provide Medical and Health Services to Pilgrims in $1439 \mathrm{H}$ Hajj Season \\ On Wednesday, the 4th of Dhu- Al hijjah $1439 \mathrm{H}$} [13], The General Authority for Statistics (GASTAT) announced within the statistical calendar of $1439 \mathrm{H}$ Hajj season, published on its official website www.stats.gov.sa, that the number of workforce provide health and ambulance services for pilgrims this season amounted to more than 31.571 capita (including 9.216 women) of the Ministry of Health, Saudi Red Crescent Authority and Saudi Food and Drug Authority members, as well as the workforce that provide health services of security and military sectors members. As well, the total number of medical and ambulance teams in holy places during Hajj season is more than 959 medical and ambulance teams providing their services to the pilgrims.

Furthermore, GASTAT has pointed out through its daily bulletin in the statistical calendar of 1439 H Hajj season that Saudi Arabia harnessed its all financial and human potential in the field of health, curative, preventive and emergency services, such as free specialized health services enhanced by the 
Ministry of Health with more than 29.495 specialized medical staffs include: doctors, pharmacists, nurses, technicians and administrators. Moreover, the health services provided to pilgrims include the following: open-heart surgery, cardiac catheterization, dialysis including both hemodialysis (HD) and peritoneal dialysis (PD), digestive endoscopies, in addition to birth deliveries and other specialized medical services needed by pilgrim patients, where the number of operating hospitals totaled 25 hospitals in Makkah and holy places. It is noteworthy that the number of health centers reached 153 centers that equipped with all health, medical and ambulatory potential, in addition to, 106 field teams in holy places as well as inside and outside Makkah, 100 small ambulances operating as mobile intensive care units in order to handle field ambulatory emergencies and 80 highly-equipped big ambulances. Ministry of Health hospitals, since the beginning of Dhul-Qa'dah till the first of Dhul-Hijjah, in terms of services provided to the pilgrims, have conducted 142 cardiac catheterization procedures, 9 open-heart surgeries, 761 dialysis (hemodialysis HD) ,39 endoscopy procedures, in addition to other 568 surgeries during the same period. Moreover, The Saudi Red Crescent Authority has allocated 127 temporary and permanent rescue centers, 361 ambulances, 20 bicycles, and more than 1861 people for the emergency teams and workforce within the area of Makka, Medina and Holy places, to provide all emergency and medical services to pilgrims.

In addition to, all health and ambulance staff works in Makkah 24 hours a day, until Sunday, 15 DhuHijjah, where the concerned entities have developed integrated programs and plans which include: providing all needs and possibilities to handle emergencies and disasters, and providing medical, preventive, therapeutic as well as ambulatory services to pilgrims, Umrah performers and Makkak as well as Prophet's Mosque visitors. These services are provided efficiently, effectively and according to a unified methodology, with latest methods of medical and ambulance care as well as with qualified cadre with practical and scientific training, to achieve the health security of holy places and the Two Holy Mosques visitors, access roads, and air as well as sea ports. It should be recalled that these services are not limited to ground service through ambulances, but also including the Saudi Air Ambulance, motorcycles, rapid response specialized team, field teams in in the Holy Mosque and the Prophet's Mosque as well as surrounding squares depending on available human resources, in addition to a constellation of volunteers (males and females).

On the other hand, The Saudi Food and Drug Authority(SFDA) handling supervisory tasks on (food, drugs and medical equipment as well as products) with pilgrims and Hajj missions as well as supporting supervisory entities responsible for the inspection of facilities that provide meals to pilgrims in Makkah, Medina and the holy places. It is worth mentioning that SFDA provides seven major services including: inspection of food, drugs and medical equipment as well as products coming through ports, health surveillance of food facilities located in the scope of Holy Makkah Municipality and Al Medina Regional Municipality, health inspection of sacrifices slaughtered in slaughterhouse in Mina place conducting field studies of food safety, raising awareness during Hajj season of the safety of food, drugs and medical equipment as well as products, in addition to inspection of transportation means entering Makkah and holy places[14].

\section{CHAPTER III}

\section{METHODOLOGY \\ INTRODUCTION}

30,200 Malaysian pilgrims and more than 200,000 Indonesian pilgrims came to the Hajj season 1440-2019. The total number of pilgrims for the year 1440-2019 is: 2,489,406, without gender preponderance. For this study, the targeted hospitals in Mena-Mena General hospital, Mena Aljisr, Mena Alwadi, and Mena Almahbat, and four hospitals in Arafat, Arafat General hospital, Jabal Alrahmah hospital, and Namera Hospital. The hospitals in Mena and Arafat are temporary health care facilities that provide essential medical services to pilgrims during the Hajj season only. The hospitals in Mena begin operation on the seventh of Dhul-Hijjah month and close on the evening of the thirteenth, whereas Arafat hospitals operate for one day only, the ninth day of Dhul-Hijjah, as pilgrims stay in Arafat only from sunrise to sunset of that day. The collected data and diagnosis data were collected from admission registry, discharge summary, and report of Saudi health minister's Closing Press Release on 1440H.-Hajj Season, 2019. 13 August, 2019. The targeted hospitals in this study are Mena Alwadi hospital (158 beds), Al Jasir hospital (152 beds), Mena general hospital (138), and Asharia hospital (50 beds), East Arafat hospital (230 beds), Namerah hospital (90 beds), Arafat general hospital (300 beds), and Al Rahmah hospital (140 beds) from the seventh to the thirteenth day of the Hajj season of the Islamic year 1440 [2], corresponding to 8 to 14 August 2019. The hospitals in Mena begin operation on the seventh of Dhul-Hijjah month and close on the evening of the thirteenth of the month, whereas Arafat hospitals operate for one day only, the ninth day of Dhul-Hijjah, as pilgrims stay in Arafat only from sunrise to sunset of that day, as shown in figure. 3.1: Sampling process. 


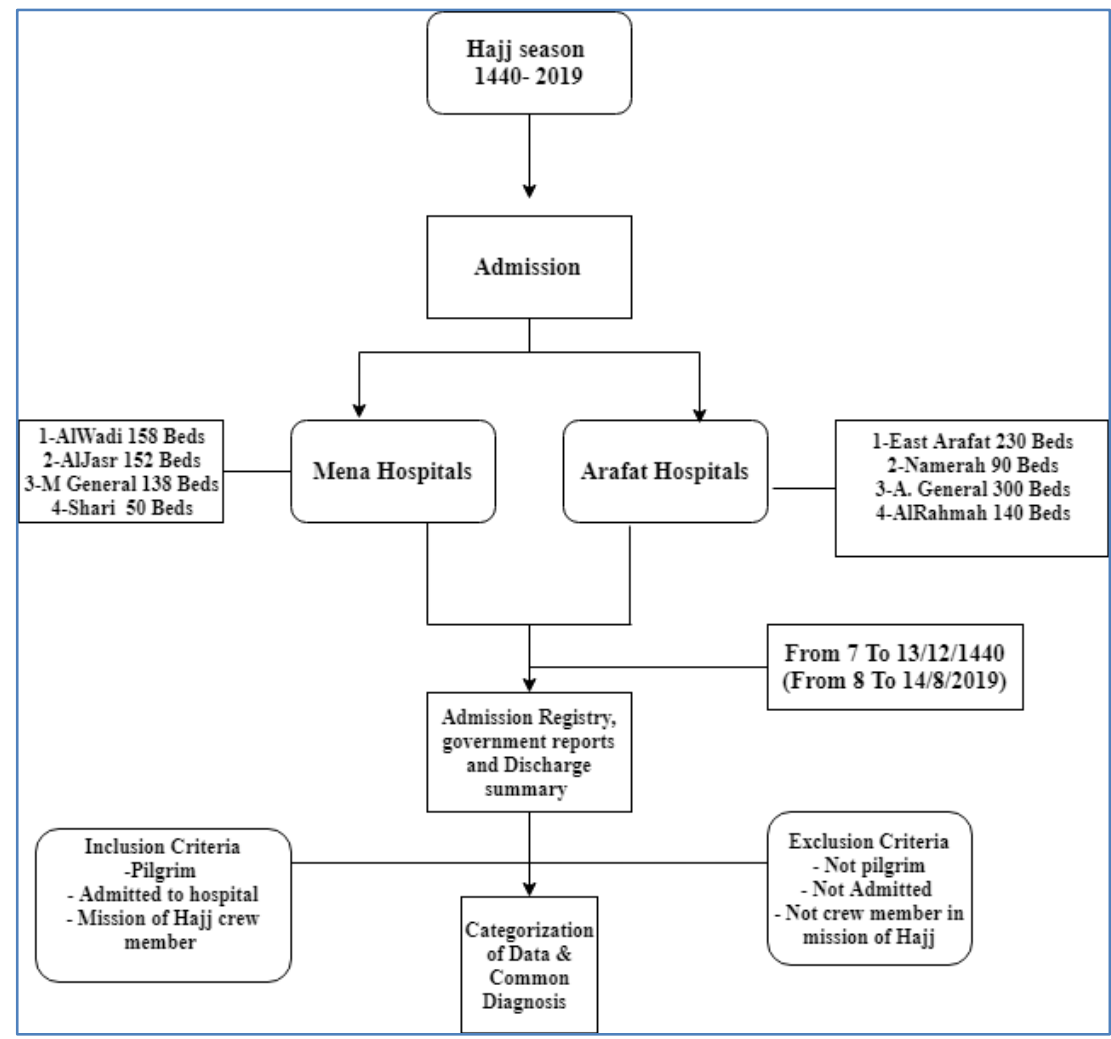

Fig-3.1: Sampling process

\section{DATA COLLECTION}

Data collection was done during Hajj season 1440-2019 from the $7^{\text {th }}$ to the $13^{\text {th }}$ day of the Hajj season of the Islamic year 1440 [2], corresponding to 8 to 14 August 2019. Using Data Survey Form (see Appendix A). The collected data and diagnosis data were collected from admission registry, discharge summary, additional to the report of Saudi health minister's Closing Press Release on 1440H.-Hajj Season, 2019. 13 August, 2019. The hospitals in Mena begin operation on the seventh of Dhul-Hijjah month and close on the evening of the thirteenth of the month, whereas Arafat hospitals operate for one day only, the ninth day of Dhul-Hijjah.

\section{CHAPTER IV}

\section{RESULT}

\section{Background}

2 Malaysian pilgrims out of 30,200 were admitted, they were older than 50 years, and 31 Indonesian pilgrims out of 200,000, most of them were older than 50 years hospitalized to the seasonal hospitals in Hajj season 1440-2019 included observation status. The total number of hospitalization in the targeted hospitals are 1398 Pilgrims, (702 Male $50.21 \%$, 696 Female $49.78 \%$ ). 1398 out of total number of pilgrims 2,489,406 (0.05\%). The common causes of admission for Malaysian and Indonesian Pilgrims in Mena and Arafat hospitals with referral are Cardiac diseases; 4 cases $(0.28 \%)$, Indonesian patients; 4 cases, Nephrological disorders included Dialysis was 1 Indonesian case $(0.07 \%)$, and pulmonary cases were; 9 cases $(0.64 \%)$, Malaysian patient; 1 case, and for Indonesian patients; 8 . As well gastrointestinal diseases; 15 cases $(1.07 \%)$, for Malaysian patient; 1, and Indonesian patients is 14 cases. The highest and the most common causes are pulmonary and gastrointestinal diseases. The collected data and diagnosis data were collected from admission registry, discharge summary, and report of Saudi health minister's Closing Press Release on 1440H.-Hajj Season, 2019. 13 August, 2019. The pilgrims stay in air-conditioned tents in Mena during the entire Hajj season, and the medical care is provided free to pilgrims by the Saudi Ministry of Health. The climate in the Hajj season in Makkah region is usually the high temperature of $24-33^{\circ} \mathrm{C}$ and a low temperature of 19 $25^{\circ} \mathrm{C}$.

Demographic characteristics of 1398 Patients (Pilgrims) admitted in Mena and Arafat hospitals in the Hajj season 1440-2019.

\begin{tabular}{|c|c|c|c|c|c|c|}
\hline & & & Mal & an Pilgrims & & Indonesian Pilgrims \\
\hline Gender & n. & $\%$ & n. & Percentage & n. & Percentage \\
\hline Male & 702 & $50.21 \%$ & 2 & $100 \%$ & 20 & $64.51 \%$ \\
\hline Female & 696 & $49.78 \%$ & 0 & 0 & 11 & $35.48 \%$ \\
\hline Total & 1398 & $100 \%$ & 2 & $100 \%$ & 31 & $100 \%$ \\
\hline
\end{tabular}




\begin{tabular}{|c|c|c|c|c|c|}
\hline \multicolumn{5}{|c|}{ Nationality * Gender Crosstabulation } & \\
\hline \multicolumn{5}{|c|}{ Count } & \\
\hline & & \multicolumn{2}{|c|}{ Gender } & \multirow{2}{*}{ Total } & \\
\hline & & Male & Female & & \\
\hline \multirow{2}{*}{ Nationality } & Malaysian & 2 & 0 & 2 & \\
\hline & Indonesian & 20 & 11 & 31 & \\
\hline \multicolumn{2}{|c|}{ Total } & 22 & 11 & 33 & \\
\hline
\end{tabular}

\begin{tabular}{|c|c|c|c|c|c|}
\hline \multicolumn{6}{|c|}{ Nationality } \\
\hline & & Frequency & Percent & Valid Percent & Cumulative Percent \\
\hline \multirow{3}{*}{ Valid } & Malaysian & 2 & 6.1 & 6.1 & 6.1 \\
\hline & Indonesian & 31 & 93.9 & 93.9 & 100.0 \\
\hline & Total & 33 & 100.0 & 100.0 & \\
\hline
\end{tabular}

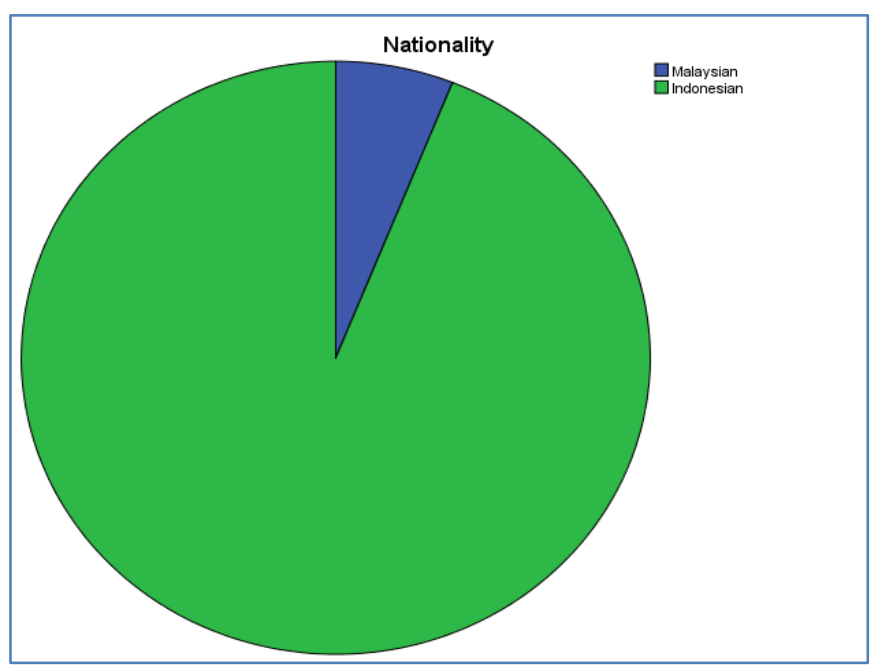

\begin{tabular}{|c|c|c|c|c|c|}
\hline \multicolumn{6}{|c|}{ Diagnosis } \\
\hline & & Frequency & Percent & Valid Percent & Cumulative Percent \\
\hline \multirow[t]{7}{*}{ Valid } & Cardiac disease & 4 & 12.1 & 12.1 & 12.1 \\
\hline & Pulmonary disease & 9 & 27.3 & 27.3 & 39.4 \\
\hline & Endocrine disease & 3 & 9.1 & 9.1 & 48.5 \\
\hline & Gastrointestinal disease & 15 & 45.5 & 45.5 & 93.9 \\
\hline & Nephrological disorders & 1 & 3.0 & 3.0 & 97.0 \\
\hline & Heat - related disease & 1 & 3.0 & 3.0 & 100.0 \\
\hline & Total & 33 & 100.0 & 100.0 & \\
\hline
\end{tabular}

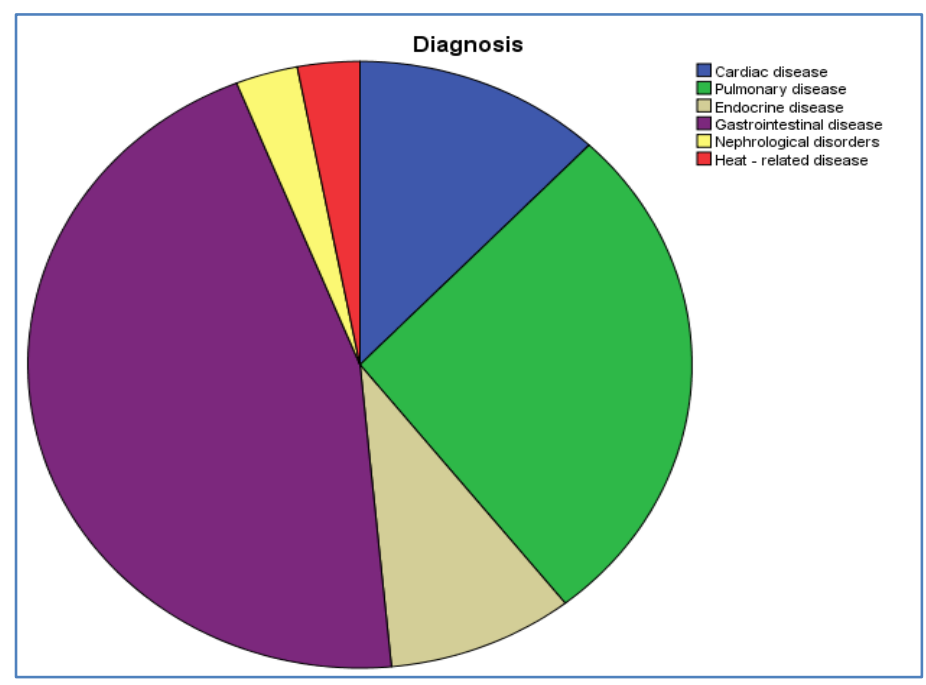




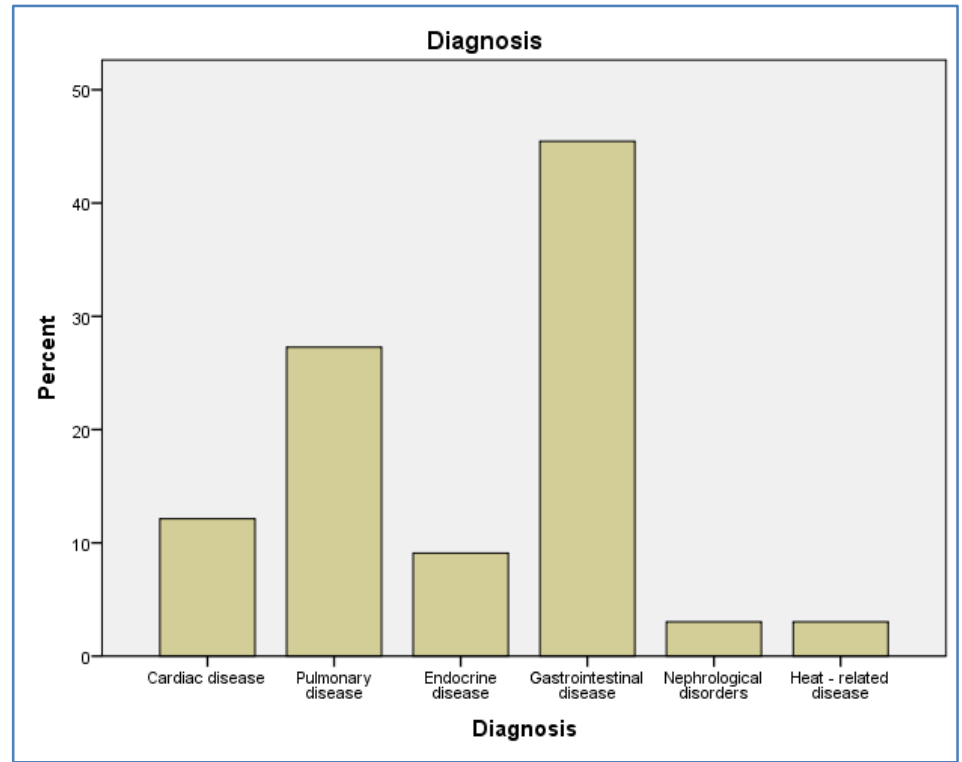

\begin{tabular}{|l|l|l|l|l|l|}
\hline \multicolumn{9}{|c|}{ Gender } \\
\hline \multirow{3}{*}{ Valid } & Frequency & Percent & Valid Percent & Cumulative Percent \\
\cline { 2 - 6 } & Female & 22 & 66.7 & 66.7 & 66.7 \\
\cline { 2 - 6 } & Total & 33 & 33.3 & 33.3 & 100.0 \\
\hline
\end{tabular}

\begin{tabular}{|l|l|r|r|r|}
\hline \multicolumn{5}{|c|}{ Nationality * Gender Cross tabulation } \\
\hline \multicolumn{2}{|c|}{ Count } & \multicolumn{2}{c|}{ Gender } & \multirow{2}{*}{ Total } \\
\cline { 3 - 5 } \multicolumn{2}{|c|}{} & Male & Female & \\
\hline \multirow{2}{*}{ Nationality } & Malaysian & 2 & 0 & 2 \\
\cline { 2 - 5 } & Indonesian & 20 & 11 & 31 \\
\hline Total & 22 & 11 & 33 \\
\hline
\end{tabular}

\begin{tabular}{|l|l|r|r|r|r|}
\hline \multicolumn{7}{|c|}{ Age } \\
\hline \multirow{3}{*}{ Valid } & $21-30$ & Frequency & Percent & Valid Percent & Cumulative Percent \\
\cline { 2 - 6 } & $31-40$ & 2 & 6.1 & 6.1 & 6.1 \\
\cline { 2 - 6 } & $41-50$ & 2 & 6.1 & 6.1 & 12.1 \\
\cline { 2 - 6 } & $51-60$ & 4 & 12.1 & 12.1 & 24.2 \\
\cline { 2 - 6 } & $61-70$ & 10 & 30.3 & 30.3 & 54.5 \\
\cline { 2 - 6 } & $71-80$ & 8 & 24.2 & 24.2 & 78.8 \\
\cline { 2 - 6 } & $81-90$ & 3 & 9.1 & 9.1 & 100.0 \\
\cline { 2 - 6 } & Total & 4 & 12.1 & 12.1 & \\
\hline
\end{tabular}

\begin{tabular}{|c|c|c|c|c|c|c|c|c|c|}
\hline \multicolumn{10}{|c|}{ Nationality * Age Cross tabulation } \\
\hline \multicolumn{10}{|l|}{ Count } \\
\hline \multirow{2}{*}{\multicolumn{2}{|c|}{ 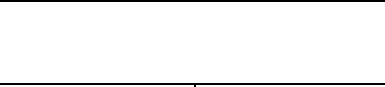 }} & \multicolumn{7}{|c|}{ Age } & \multirow[t]{2}{*}{ Total } \\
\hline & & $21-30$ & $31-40$ & $41-50$ & $51-60$ & $61-70$ & $71-80$ & $81-90$ & \\
\hline \multirow[t]{2}{*}{ Nationality } & Malaysian & 0 & 0 & 0 & 1 & 1 & 0 & 0 & 2 \\
\hline & Indonesian & 2 & 2 & 4 & 9 & 7 & 3 & 4 & 31 \\
\hline \multicolumn{2}{|l|}{ Total } & 2 & 2 & 4 & 10 & 8 & 3 & 4 & 33 \\
\hline
\end{tabular}

\begin{tabular}{|l|l|r|r|r|r|}
\hline \multicolumn{7}{|c|}{ Marital Status } \\
\hline \multirow{3}{*}{ Valid } & single & Frequency & Percent & \multicolumn{1}{c|}{ Valid Percent } & Cumulative Percent \\
\cline { 2 - 6 } & Married & 2 & 6.1 & 6.1 & 6.1 \\
\cline { 2 - 6 } & Total & 31 & 93.9 & 93.9 & 100.0 \\
\hline
\end{tabular}




\begin{tabular}{|l|l|r|r|r|}
\hline \multicolumn{4}{|c|}{ Nationality * Marital Status Cross tabulation } \\
\hline \multicolumn{2}{|c|}{ Count } & \multicolumn{2}{|c|}{ Martitalstatus } & \multirow{2}{*}{ Total } \\
\cline { 3 - 4 } \multicolumn{2}{|c|}{} & single & Married & \\
\hline \multirow{2}{*}{ Nationality } & Malaysian & 0 & 2 & 2 \\
\cline { 2 - 5 } & Indonesian & 2 & 29 & 31 \\
\hline Total & 2 & 31 & 33 \\
\hline
\end{tabular}

\begin{tabular}{|l|l|r|r|r|r|}
\hline \multicolumn{9}{|c|}{ Location } \\
\hline \multirow{3}{*}{ Valid } & Mena & \multicolumn{1}{|c|}{ Frequency } & Percent & Valid Percent & Cumulative Percent \\
\cline { 2 - 6 } & Arafat & 24 & 72.7 & 72.7 & 72.7 \\
\cline { 2 - 6 } & Total & 9 & 27.3 & 27.3 & 100.0 \\
\hline
\end{tabular}

\begin{tabular}{|l|l|r|r|r|}
\hline \multicolumn{4}{|c|}{ Nationality * Location Cross tabulation } \\
\hline \multicolumn{2}{|c|}{ Count } & \multicolumn{2}{|c|}{ Location } & \multirow{2}{*}{ Total } \\
\cline { 3 - 4 } \multicolumn{2}{|c|}{} & Mena & \multicolumn{1}{|c|}{ Arafat } & \\
\hline \multirow{2}{*}{ Nationality } & Malaysian & 1 & 1 & 2 \\
\cline { 2 - 5 } & Indonesian & 23 & 8 & 31 \\
\hline \multicolumn{2}{|l|}{ Total } & 24 & 9 & 33 \\
\hline
\end{tabular}

\begin{tabular}{|l|l|l|l|l|l|}
\hline \multicolumn{2}{|c|}{ Hospital } & Frequency & Percent & Valid Percent & Cumulative Percent \\
\hline \multicolumn{1}{|c|}{} & Mena al wadi & 7 & 21.2 & 21.2 & 21.2 \\
\cline { 2 - 6 } & Al Jasir & 4 & 12.1 & 12.1 & 33.3 \\
\cline { 2 - 6 } & Mena general hospital & 12 & 36.4 & 36.4 & 69.7 \\
\cline { 2 - 6 } & Asharia & 1 & 3.0 & 3.0 & 72.7 \\
\cline { 2 - 6 } & East Arafat & 1 & 3.0 & 3.0 & 75.8 \\
\cline { 2 - 6 } & Namerah & 3 & 9.1 & 9.1 & 84.8 \\
\cline { 2 - 6 } & Arafat general hospital & 4 & 12.1 & 12.1 & 97.0 \\
\cline { 2 - 6 } & Al Rahmah & 1 & 3.0 & 3.0 & 100.0 \\
\cline { 2 - 6 } & Total & 33 & 100.0 & 100.0 & \\
\hline
\end{tabular}

\begin{tabular}{|l|l|l|l|l|l|}
\hline \multicolumn{2}{|c|}{ DOA } \\
\hline \multirow{4}{*}{} & Frequency & Percent & Valid Percent & Cumulative Percent \\
\cline { 2 - 6 } & $8 / 8 / 2019$ & 6 & 18.2 & 18.2 & 18.2 \\
\cline { 2 - 6 } & $9 / 8 / 2019$ & 2 & 6.1 & 6.1 & 24.2 \\
\cline { 2 - 6 } & $10 / 8 / 2019$ & 10 & 30.3 & 30.3 & 54.5 \\
\cline { 2 - 6 } & $11 / 8 / 2019$ & 7 & 21.2 & 21.2 & 75.8 \\
\cline { 2 - 6 } & $12 / 8 / 2019$ & 3 & 9.1 & 9.1 & 84.8 \\
\cline { 2 - 6 } & $13 / 8 / 2019$ & 4 & 12.1 & 12.1 & 97.0 \\
\cline { 2 - 6 } & $14 / 8 / 2019$ & 1 & 3.0 & 3.0 & 100.0 \\
\cline { 2 - 6 } & Total & 33 & 100.0 & 100.0 & \\
\hline
\end{tabular}

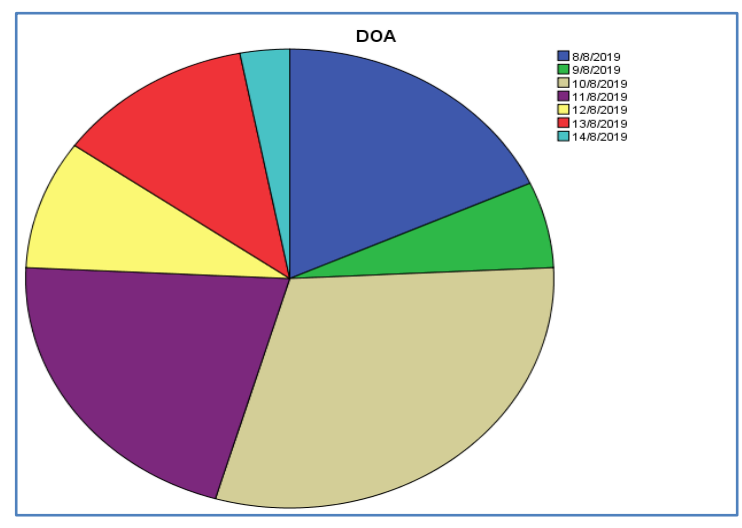



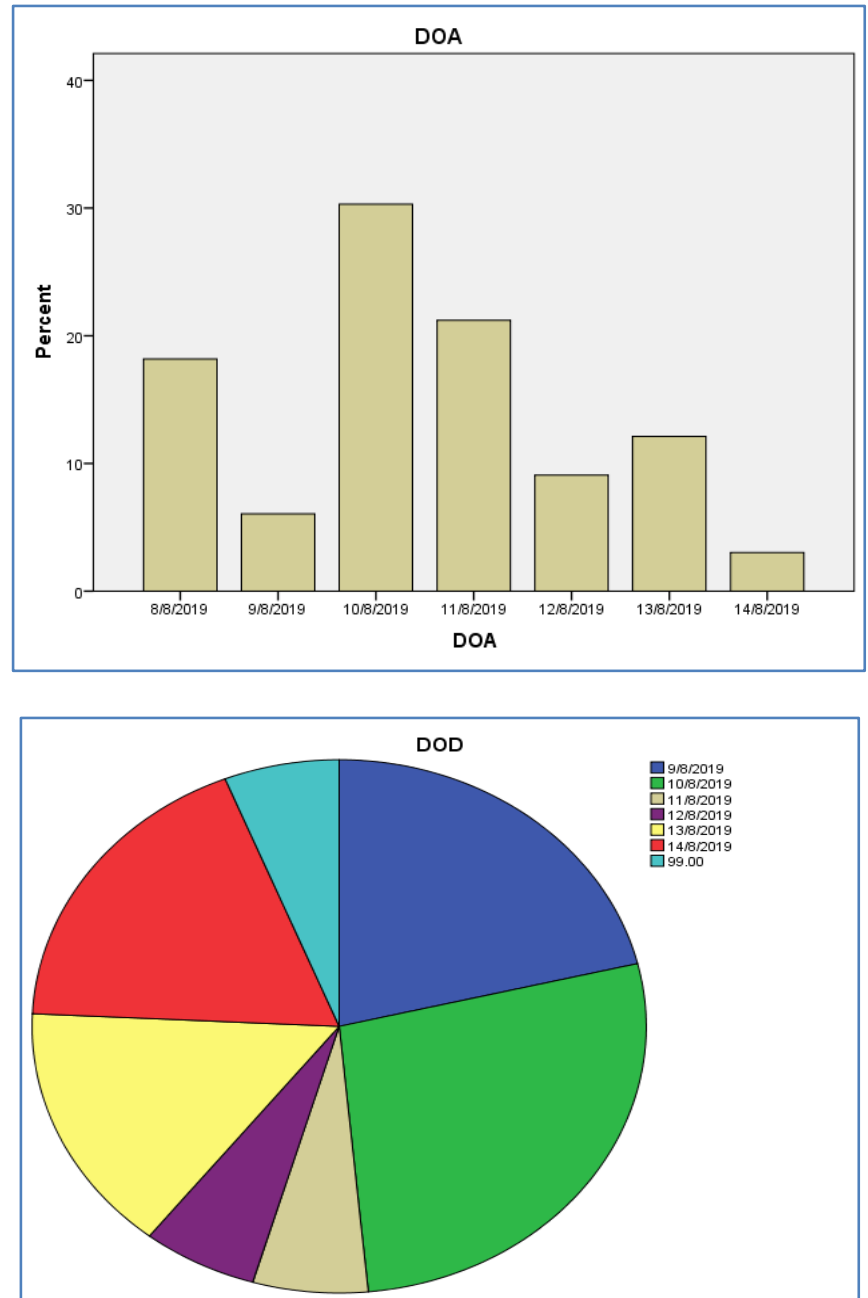

\begin{tabular}{|l|l|r|r|r|r|}
\hline \multicolumn{2}{|c|}{ DOD = Date of Discharge Section } \\
\hline \multirow{2}{*}{} & \multicolumn{2}{|c|}{ Frequency } & \multicolumn{1}{|c|}{ Percent } & Valid Percent & Cumulative Percent \\
\hline \multirow{6}{*}{ Valid } & FMW & & & & 24.2 \\
\cline { 2 - 6 } & MMW & 15 & 24.2 & 24.2 & 69.7 \\
\cline { 2 - 6 } & CCU & 3 & 9.1 & 45.5 & 78.8 \\
\cline { 2 - 6 } & ER Observation & 6 & 18.2 & 9.1 & 97.0 \\
\cline { 2 - 6 } & 99.00 & 33 & 100.0 & 18.2 & 100.0 \\
\cline { 2 - 6 } & Total & & 3.0 & 100.0 & \\
\hline
\end{tabular}

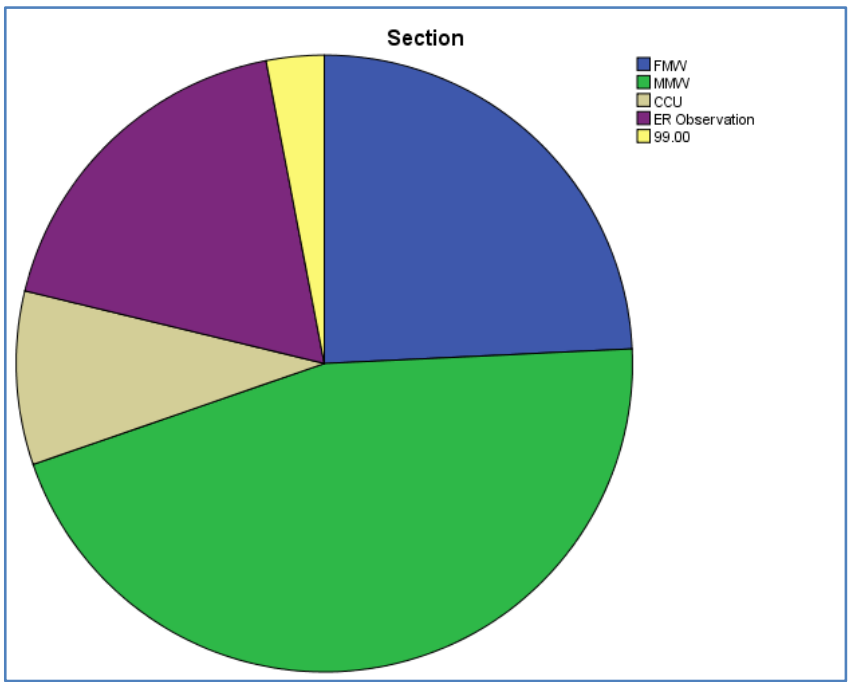


$\mathrm{DOA}=$ Date of Admission

\begin{tabular}{|c|c|c|c|c|c|c|c|c|}
\hline \multicolumn{9}{|c|}{ Nationality * Diagnosis Crosstabulation } \\
\hline \multicolumn{9}{|c|}{ Count } \\
\hline & & \multicolumn{6}{|c|}{ Diagnosis } & \multirow[b]{2}{*}{ Total } \\
\hline & & $\begin{array}{l}\text { Cardiac } \\
\text { disease }\end{array}$ & $\begin{array}{l}\text { Pulmonary } \\
\text { disease }\end{array}$ & $\begin{array}{l}\text { Endocrine } \\
\text { disease }\end{array}$ & $\begin{array}{c}\text { Gastrointestinal } \\
\text { disease }\end{array}$ & $\begin{array}{l}\text { Nephrological } \\
\text { disorders }\end{array}$ & $\begin{array}{l}\text { Heat - } \\
\text { related } \\
\text { disease }\end{array}$ & \\
\hline \multirow{2}{*}{ Nationality } & Malaysian & 0 & 1 & 0 & 1 & 0 & 0 & 2 \\
\hline & Indonesian & 4 & 8 & 3 & 14 & 1 & 1 & 31 \\
\hline \multicolumn{2}{|c|}{ Total } & 4 & 9 & 3 & 15 & 1 & 1 & 33 \\
\hline
\end{tabular}

\section{CONCLUSION}

This study identified the most common causes of Malaysian and Indonesian pilgrims' hospitalization during the hajj season 1440, 2019 in Mena and Arafat hospitals. This study provided information on the causes of Malaysian and Indonesian pilgrims' hospitalization during the Hajj season 14402019 in Mena and Arafat Hospitals, and the required medical services for pilgrims in Hajj season. Hajj is the fifth of the five pillars of Islam. The Hajj begins on the eighth day of Dhul-Hijjah, the twelfth month of the Islamic year, and ends on the thirteenth day of the same month. Hajj has to be performed in three main locations in Makkah, and this study was done in two locations, Mena and Arafat. In this study we describe the outcomes of Malaysian and Indonesian pilgrims who admitted during the Hajj season of the Islamic year 1440,2019 . In this study, the majority $(30.3 \%)$ of hospitalized patients were older than 50 years and more than one third $(24.2 \%)$ of patients were older than 60 years. More than $(93.9 \%)$ of patients were from Indonesia, and $(6.1 \%)$ were from Malaysia. Most of the patients $(54.54 \%)$ were discharged from the hospital within a maximum of 24 hours of admission. This short hospitalization was observation of patients, and discharged from the hospital as soon as possible so that they would be able to complete the Hajj rituals and to free hospital beds to accommodate the big influx of patients requiring hospitalization in the Hajj period. The common causes of Malaysian and Indonesian pilgrims' admission in Mena and Arafat hospitals were gastrointestinal disease 15 cases $(45.5 \%)$ for Malaysian patient; 1, and Indonesian cases were 14 cases. Pulmonary diseases; 9 cases $(27.3 \%)$, Malaysian patient; 1 case, and Indonesian cases were 8 . and cardiac diseases with referral; 4 cases (12.1\%), Indonesian patients; 4 cases, endocrine disease 3 cases $(9.1 \%)$ were Indonesian patients. Nephrological disorders included Dialysis; 1 case $(3.0 \%)$, was Indonesian patient. The heat - related disease; 1 case $(3.0 \%)$ was Indonesian pilgrim. So, the highest and the Most common causes were gastrointestinal and pulmonary diseases. The outcomes of the patients who discharged against medical advice was not studied.

\section{REFERENCES}

1. Health Minister's Closing Press Release on 1440H.-Hajj Season. (2019). 13 August, 2019. https://www.moh.gov.sa/en/Ministry/MediaCenter/
News/Pages/news-2019-08-13-009.aspx

2. Ministry of Health - (MOH). (2019). Health Minister's Closing Press Release on 1440H.HajjSeason,2019.13August,2019.https://www.moh. gov.sa/en/Ministry/MediaCenter/News/Pages/news -2019-08-13-009.aspx

3. Radhiah, N., Rosminah, M., Suhaimi, A. W., \& Omar, O. (2017). The Fundamental Of Hajj Demand For Health Care Services Within Congestion In Makkah. Malaysian Journal of Public Health Medicine, 17(1), 84-93.

4. Siti, A., SuMiman, M. D., Mohd, S., \& Wahab, M. D. (2007). Preference of treatment facilities among Malaysian Hajj pilgrims for acute respiratory symptoms. Ann Saudi Med, 27, 105.

5. Hashem, A. M., Al- Subhi, T. L., Badroon, N. A., Hassan, A. M., Bajrai, L. H. M., Banassir, T. M., ... \& Azhar, E. I. (2019). MERS- CoV, influenza and other respiratory viruses among symptomatic pilgrims during 2014 Hajj season. Journal of medical virology, 91(6), 911-917.

6. Al Masud, S. M. R., Bakar, A. A., \& Yussof, S. (2016). Determining the types of diseases and emergency issues in Pilgrims during Hajj: A literature review. Stat Inf, 5, 7.

7. Madani, T. A., Ghabrah, T. M., Al-Hedaithy, M. A., Alhazmi, M. A., Alazraqi, T. A., Albarrak, A. M., \& Ishaq, A. H. (2006). Causes of hospitalization of pilgrims during the Hajj period of the Islamic year 1423 (2003). Annals of Saudi medicine, 26(5), 346-351.

8. Mirza, A. A., Al-Sakkaf, M. A., Mohammed, A. A., Farooq, M. U., Al-Ahmadi, Z. A., \& Basyuni, M. A. (2018). Patterns of Inpatient Admissions during Hajj: Clinical conditions, length of stay and patient outcomes at an advanced care centre in Makkah, Saudi Arabia. Pakistan journal of medical sciences, 34(4), 781.

9. Alzeer, A., Mashlah, A., Fakim, N., Al-Sugair, N., Al-Hedaithy, M., Al-Majed, S., \& Jamjoom, G. (1998). Tuberculosis is the commonest cause of pneumonia requiring hospitalization during Hajj (pilgrimage to Makkah). Journal of infection, 36(3), 303-306.

10. Al-Ghamdi, S. M., Akbar, H. O., Qari, Y. A., Fathaldin, O. A., \& Al-Rashed, R. S. (2003). Pattern of admission to hospitals during muslim pilgrimage (Hajj). Saudi medical journal, 24(10), 1073-1076. 
11. Khogali, M. (1983). Epidemiology of heat illnesses during the Makkah Pilgrimages in Saudi Arabia. International journal of epidemiology, 12(3), 267-273.

12. Al-Mazrou, Y. Y., Al-Jeffri, M. H., Abdalla, M. N., Elgizouli, S. A., \& Mishskas, A. A. (2004). Changes in epidemiological pattern of Meningococcal disease in Saudi Arabia. Does it constitute a new challenge for prevention and
control?.Saudi medical journal,25(10), 14101413.

13. Ministry of Health - (MOH). (2018). (online) available at http://www.moh.gov.sa

14. The General Authority for Statistics (GASTAT), 2018. The statistical calendar of 1439 H Hajj season,(online) available https://www.stats.gov.sa/en/ (accessed 9 Feb 2019).

\section{Appendix A \\ Hajj 1440-2019 SURVEY}

\section{SOCIODEMOGRAPHIC INFORMATION}

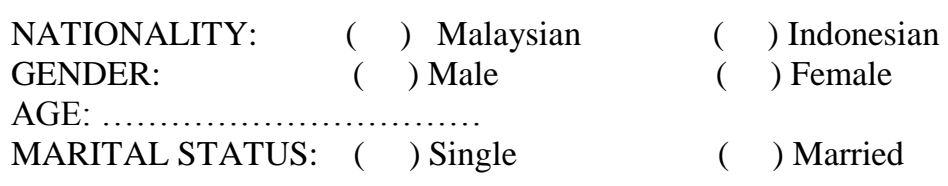

\section{ADMISSION INFORMATION}

Location,

\begin{tabular}{|c|c|c|c|}
\hline \multirow{4}{*}{ Mena } & Mena Alwadi hospital & \multirow{4}{*}{ Arafat } & East Arafat hospital \\
\hline & Al Jasir hospital & & Namerah hospital, \\
\hline & Mena general hospital & & Arafat general hospital \\
\hline & Asharia hospital & & Al Rahmah hospital \\
\hline
\end{tabular}

DATE OF ADMISSION:

.$/ 2019$

.../ $12 / 1440$

DATE OF DISCHARGE:

/ 2019-

.../ $12 / 1440$

SECTION.

CAUSE OF ADMISSION. 